\title{
DISEÑO DE UN SITIO WEB QUE GENERE UN NEXO INTEGRAL -ECONÓMICO, SOCIAL, EDUCATIVO Y DE RECONOCIMIENTO- ENTRE LOS TATUADORES Y SUS CLIENTES DE LA CIUDAD DE PASTO
}

\section{Entorno Cultura}

Sebastián Cabrera Jiménez

sebas9685@gmail.com

Universidad de Nariño.

MURU Investigación, Creación y Diseño.

Pasto, Nariño. 


\section{Resumen}

CI estudio nace de la necesidad de aportar desde el Diseño, al nexo que existe entre los - centros de tatuaje y sus clientes. El propósito del Diseño de servicios en el mundo del tatuaje, es mejorar el servicio ofrecido por los artistas, al hacer que su imagen comercial sea la adecuada para sus clientes habituales o futuros. La intervención del Diseño Gráfico en esta industria, resulta adecuada al generar artefactos comunicacionales tangibles e intangibles que colaboran en la difución de un arte milenario en la región. En los últimos años, la cantidad de personas tatuadas ha aumentado, lo cual indica una consolidación de la cultura del tatuaje, a pesar de los problemas como la informalidad, el desconocimiento de las personas que ejercen el oficio y el regionalismo. Estos factores han hecho que el arte del tatuaje en la ciudad de Pasto, aún sea asumido con un tono tradicional en su difusión y sin presencia substancial a nivel nacional. A través del Diseño Gráfico puede promocionarse y crecer, con la consiguiente generación de beneficios a nivel social, económico y cultural. Así, la solución planteada para mejorar el nexo entre tatuadores y clientes, tiene como base una metodología proyectual basada en los estudios de Bruno Munari y Morris Asimow junto con el pensamiento de diseño como herramienta inherente al proceso de ideación, prototipado y testeo. El estudio concluyó que el servicio de diseño se expresa a través de la experiencia que obtiene el usuario al utilizar el sitio web, acompañado de la obtención de un tatuaje. El conjunto de opciones develadas por el uso a pronfundidad del sitio web, crea en el usuario valor y empatia, para permanecer y continuar usando Tattoo Finder.

\section{Introducción}

El arte de tatuar es una práctica milenaria ligada con el origen de la humanidad; constituido como una expresión cultural que diferencia de manera estética y espiritual a sus portadores. En cada región donde han surgido los tatuajes, se han desarrollado estilos y técnicas que hoy en día se difunden a través de una comunidad global de tatuadores y tatuados.

Dentro del objeto de estudio del proyecto, el nexo que existe entre tatuadores y sus clientes presenta aspectos dentro del servicio, que pueden mejorarse por medio del Diseño, como puede ser la atención al cliente, conocimiento del procedimiento, imagen corporativa de la empresa y experiencia previa, durante y después de la aplicación del tatuaje. Es preciso señalar, que la intervención del Diseño en la actual industria del tatuaje, puede generar una eficaz propuesta comunicativa que beneficie a los involucrados, ya que, no obstante contar con una oferta estable y demanda de tataujes en la ciudad de Pasto, el servicio en general es tradicional y básico, lo que va en detrimento de oportunidades para evolucionar y sobresalir en el mercado nacional e internacional.

Así entonces, el proyecto en cuestión pretende realizar un significativo aporte desde el Diseño gráfico, a través de un artefacto comunicativo digital dirigido a tataudores y tatuados, para facilitar el flujo de información entre ellos y, en consecuencia, añadir un plus al servicio que ofrecen. 
De las multiples herramientas y metodologías ofrecidas por la escuela de Diseño Gráfico, en especifico, se ha optado por las que mejoren los aspectos de identidad corporativa, diseño de servicios y diseño web. Una vez concluido el proyecto, éste beneficiará a los centros de tatuaje y a sus usuarios, al brindar un servicio efectivo que se abre a la actualización e innovación en la comunidad de tatuadores de Pasto.

\section{Metodología}

La investigación se basó en las metodologías propuestas por Morris Asimov y Bruno Munari (Lozano \& Calao, 2016; Sánchez Blasco, 2011), las cuales combinan dos métodos lógicos y detallados, con el dinamismo del pensamiento creativo para trabajar con el usuario en todo momento. Su objetivo es obtener información subjetiva y que, a la vez, encaje en un proceso de diseño estructurado. Esto quiere decir que, con información obtenida a través de un trabajo de campo, se pueda utilizar para diseñar un artefacto al seguir unos pasos pre-establecidos.

Los pasos a seguir, en la metodología, no se rigen por un orden secuencial, y el regreso entre ellos es permitido en caso de que el investigador necesite replantear conceptos. El uso intrínseco de algunos aspectos del pensamiento de diseño, como la empatía, se incorporaron en la metodología, para poder desarrollar una investigación basada en el vínculo con el usuario.

Por lo tanto, el primer paso consistió en definir el problema a tratar, tal y como lo plantean los autores, para dar inicio a la investigación con el establecimiento de ciertos límites. Los siguientes tres pasos correspondieron a una recolección de información y su posteriror análisis en sub-problemas -Munari describe este método, como una manera práctica de abordar el problema global y hacer más fácil su comprensión y posterior solución; Asimov, al igual que Munari, plantea seguir esta primera fase a través de una planeación detallada, producto del intenso análisis de la información obtenida-.

A continuación se procedió con la etapa de diseño, la que inició con la generación de ideas creativas dentro de un marco de realidad y posiblidad, que permitan al investigador dar solución a los sub-problemas. Para la fase final de implementación y testeo, se realizó la creación de prototipos que constatnemente se probaron con el usuario, para obtener un feedback y su posterior análisis. Asimov propone el diseño completo y detallado de componentes, planos, partes y componentes del prototipo, lo cual se tuvo en cuenta para esta investigación.

El último paso después de realizar el testeo de prototipos, fue la implementación del producto luego de haber recibido el correspondiente feedback por parte de los usuarios, tal y como lo plantean los autores citados. 


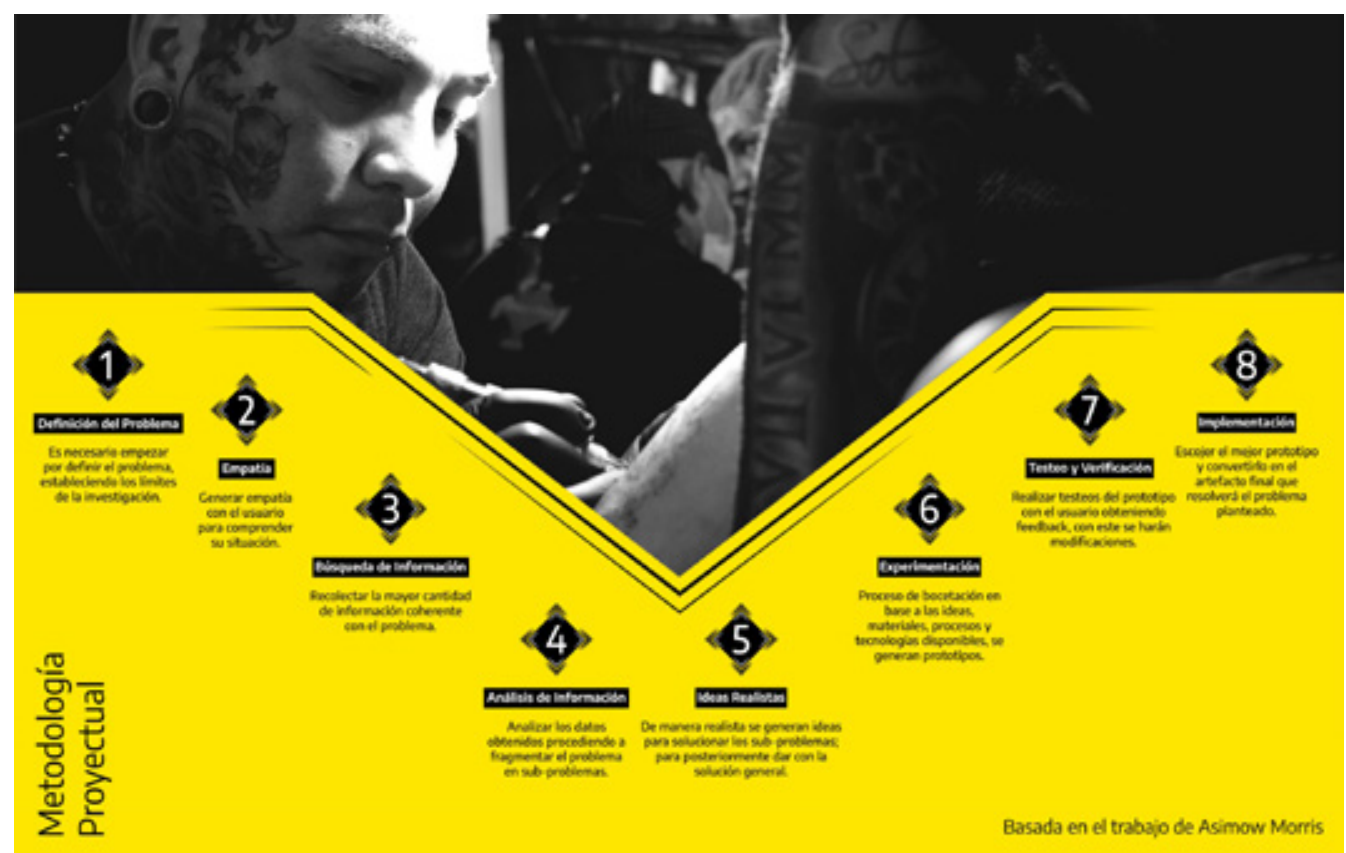

Figura 1. Metodología proyectual

\section{Resultados}

Se realizó un testeo con algunos tatuadores y personas con gusto por los tatuajes, en diferentes lugares como estudios y convenciones, para probar la funcionalidad del sitio web. Se analizó el comportamiento del usuario al navegar, su parecer al contenido y medir, mediante observación objetiva, lo que se debe mejorar. Se observó que, en general, a los usuarios les parece una buena idea integrar los tatuajes en un sitio web y poder encontrar contenido regional en un solo lugar.

La respuesta de los centros de tatuaje fue de completa aceptación, al responder positivamente al aspecto gráfico del proyecto; así mismo, se presentó un alto interés por colaborar con el desarrollo de la investigación, para una futura implementación total. Un factor clave registrado en común, fue la facilidad del usuario al navegar por el sitio en contados clic, para descubrir información nueva que le llamara la atención.

De suerte que optar por una estética con base en fotorgrafías, iconos, ilustraciones y referencias de tatuajes fue un acierto, al encontrar un equilibrio entre el lenguaje escrito y el visual en la cantidad de información presenada. 
A continuación se presentan los aspectos técnicos y de análisis más relevantes de los

testeos realizados:

- Optar por un menú fijo en todas las páginas resultó efectivo, ya que los usuarios lo utilizan para acceder a las diferentes sub-páginas y de la misma manera regresar al inicio.

- Ventanas de contenido con los botones suficientes, generaron una respuesta rápida e intuitiva para continuar navegando; entre más sencillo y directo es mejor.

- Los tatuadores piensan que estar todos juntos en una plataforma web, hará que su reconocimiento crezca; esto es posible si los filtros de aceptación son los adecuados para entrar al sitio web.

- Se confirmó que una navegación horizontal, o de pantalla completa, es más efectivo que listar toda la información en páginas verticales, ya que los usuarios acceden al contenido en pocos clic.

- La interactividad con el sitio web, posibilita una experiencia nueva para conseguir, mirar o comentar sobre tatuajes en la ciudad de Pasto.

- La creación de los perfiles Tattoo Finder, dio una nueva mirada a los tatuadores, demostrando estar al nivel de sus trabajos.

- Las opciones interactivas: prueba de tatuaje y juegos de lucifer se mostraron como innovadoras y diferentes a los ojos de los usuarios.

- El uso de formularios para manejar las citas en línea, representa una alternativa funcional para los centros de tatuaje y sus clientes, al mostrar la información de una manera más organizada.

- La adaptación del sitio web a diferentes dispositivos móviles, es, sin duda, un requisito que se ha cumplido a cabalidad, al responder al comportamiento del usuario en la era digital actual.

\section{Conclusiones}

El servicio de diseño se expresa a través de la experiencia que obtiene el usuario al utilizar el sitio web, acompañado de la obtención de un tatuaje.

El conjunto de opciones develadas por el uso a pronfundidad del sitio web, crea en el usuario valor y empatia, para permanecer y continuar usando Tattoo Finder.

\section{Referencias}

Lozano, E. \& Calao, J. (31 de marzo de 2016). El método proyectual de Morris Asimow [Contenido en sitio web]. Recuperado de https://es.slideshare.net/EstebanLozano2/ metodologia-morris-asimow

Sánchez Blasco, L. (marzo, 2011). Metodología proyectual por Bruno Munari. Cosas de Arquitectos. Revista Digital. Recuperado de https://www.cosasdearquitectos. com/2011/03/metodologia-proyectual-por-bruno-munari/ 


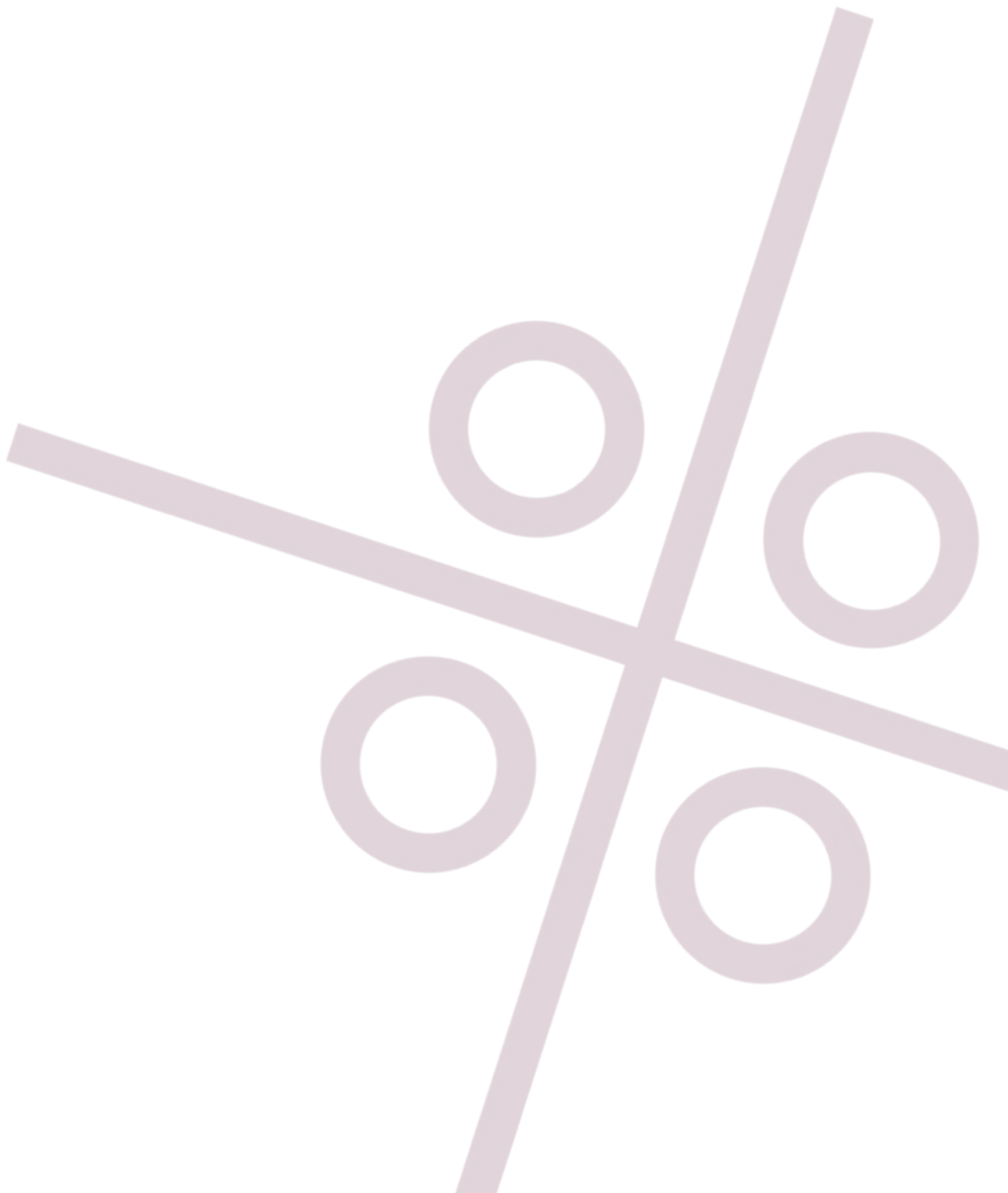

